\title{
Gáfestallan Talks of the Indigenous Research Paradigm in Sámi Research
}

\author{
Pigga Keskitalo, Torkel Rasmussen, Rauna Rahko-Ravantti and \\ Rauni Ä̈rrelä-Vihriälä
}

\begin{abstract}
This chapter continues the discussion on an Indigenous research paradigm involving Indigenous research methodologies based on existing theories and the authors' experience. We present our own experiences of conducting our $\mathrm{PhD}$ research projects in social sciences and teaching Sámi higher education programmes. We retrospectively evaluate the research processes we used in writing our $\mathrm{PhD}$ dissertations, with particular attention to how we implemented an Indigenous research methodology. The literature review demonstrates that Indigenous scholars frequently find that the Western research paradigm overpowers students' research. We also found that, consciously or unconsciously, we as researchers fitted our own research projects into an Indigenous research paradigm when we conducted our research. There is a growing awareness in our research environments that Sámi research should be conducted in a different way than mainstream research is. We also see a need for an ongoing effort to develop supportive practices incorporating a structured awareness of Indigenous methodologies.
\end{abstract}

\section{Keywords}

paradigm shift - Indigenous research paradigm - Indigenous research - Sámi research - relational knowledge

\section{Introduction}

There has been a repeated call for a paradigm shift in Indigenous research, and we have seen some serious attempts to investigate how to develop and implement a distinct research paradigm in Indigenous research. It started over 20 years ago, when Linda Tuhiwai Smith (1999/2012) emphasized the need to decolonize the research methods of the European tradition in her critical 
examination of Western philosophy and history. Smith argued that researchers must reject the Western paradigm and move away from imperialism and towards post-colonization. The fundamental theme of this article is the assertion that it is difficult even to clearly define the core terminology needed to construct an Indigenous research paradigm. For example, 'research paradigm' and 'Western research paradigm' are complicated and overlapping terms. This inspired us to investigate these terminologies theoretically before conducting a critical analysis of our own earlier research projects and teaching practices.

The term 'paradigm' is a label for a set of beliefs which go together to guide a person's actions. Researchers often refer to Thomas Kuhn for a definition of a research paradigm. A research paradigm is "the set of common beliefs and agreements shared between scientists about how problems should be understood and addressed" (Kuhn 1962/2012, 43). The various research paradigms, the differences between them and their perspectives are focal points for developing and constructing Indigenous research (Wilson 2001, 175). On the other hand, Maggie Walter and Chris Andersen (2016) identified a problem that there is no common, widely accepted definition of what a research methodology or a research paradigm is.

After reviewing different research literature, we chose as a basis for understanding the Indigenous research paradigm, the work of Shawn Wilson (2001), who handled the research paradigm holistically as a label with four main parts. Wilson's four aspects of a research paradigm are: (1) ontology, i.e. your way of being and what you believe; (2) epistemology, which is how you think about reality; (3) research methodology, or the way in which you are going to use your way of thinking, your epistemology, to gain more knowledge about your reality; and finally (4) axiology, which consists of ethics and judging what research is worth doing in different paradigms (Wilson 2001, 175).

This is why we focused our analysis on what we as researchers think and how this thinking affects our personal behaviours and actions during the research process. In this case, we investigated our own thinking and how it guided our behaviour and actions during our research, from designing a research project, the process of conducting the research, up to the publishing phase and beyond, following up with our research partners and considering the possible impact of our projects.

\subsection{Setting the Scene for Analyzing Paradigms}

During the Network for Indigenous Methods in Academia 2017-2019 we set up a working group to analyze our own practices as researchers and educators in Sámi higher education. The members of the working group have been colleagues and acquaintances for years and have had various connections to each other as scholars. We have gathered together to discuss different issues on 
numerous occasions in both informal and professional settings. However, this project gave us the opportunity and setting to sit down to discuss our respective understandings of Indigenous methodologies and to evaluate our work.

The workshops became a space of self-reflection, cooperative team-reflection and shared knowledge-building. We established a space for evaluating how we understood and implemented Indigenous research methods and methodologies in our own research, development projects and educational tasks. In these joint meetings, we dealt with the question of what we could have done if we had been more conscious, had had greater knowledge and had been more involved in the process of creating Indigenous methodologies. This can be described as self-evaluating our research processes in the light of research paradigms and the need to reconstruct them within the Sámi research context, analogous to a framework of relational Indigenous research methodologies (see Wilson 2001).

We began by analyzing research literature and our own actions as researchers and educators at gáfestallan talks, which are the Sámi way of 'talking circles' (see also Löf \& Stinnerbom 2016, 147). Gáfestallan actually means 'coffee break' in North Sámi, and it is also a moment for sitting down, exchanging ideas, planning, and making decisions. The idea of gáfestallan talking circle can be transformed into a methodological tool to produce knowledge and to consider the research context holistically. We shared our experiences of completing PhDs on Sámi issues in Nordic universities. We decided to individually analyze our own PhD texts (Keskitalo 2010; Rasmussen 2013; Äärelä 2016; Rahko-Ravantti 2016) according to the demands we found most often highlighted in Indigenous research methodologies.

As a next step we agreed in the working group to write down our experiences, circulate them and discuss them during Skype calls before we conducted a new gáfestallan talking circle discussion at one of the face-to-face sessions during the network event. This time we addressed a specific question: Did we really do anything wrong and/or inappropriate in our research projects? We also discussed what was successful in our research processes. In her book Reshaping the University, Rauna Kuokkanen (2007) hoped for an upheaval in the world of science in which aggressive power struggles would be replaced by participation and commitment. This meant sharing our diverse perspectives on, and representations of, different aspects and phases of research. We observed that progress had been made, including some of the fundamental changes described by Kuokkanen (2007).

Indigenous research methods also involve talking about positioning and backgrounds - where we belong as Sámi and researchers. In the working group discussions, we talked about how we became researchers and shared our narratives, how we started to work and how our reference groups were formed. The crucial question from the beginning to the end of the research process 
was how we were connected to our communities as members, researchers and educators. According to Wilson (2001), a relationship requires connectedness to the community and the culture one is researching, as well as its ontology and worldview. This is necessary to establish a true partnership and to conduct sound research. We found these requirements essential in our former research projects. Establishing these relationships was time-consuming and sometimes expensive, as it necessitated a lot of travelling.

We analyzed our research and education processes as attempts to adjust to the system by combining mainstream universities and their Western research methodologies with Indigenous research methodologies. Inevitably, we all had to work with the strong impact of Western research methodologies because we are all Indigenous scholars who completed $\mathrm{PhD}$ degrees at mainstream universities. Our research might have gaps, as we all conducted our research within the educational and Sámi language context and at mainstream universities. In retrospect, we wrote our $\mathrm{PhD}$ dissertations to the best of our abilities and contributed to the creation of an Indigenous research methodologies. During our $\mathrm{PhD}$ research some of us were part of bigger research groups, which made us feel that our projects were accepted, guided and secured by the Sámi research community as well as the wider Sámi community. The Sámi University of Applied Sciences became a joint working and meeting place for all of us as scholars and lecturers, as we had all worked there and two of our $\mathrm{PhD}$ projects were funded and connected to research projects in the Sámi University of Applied Sciences. We feel that we are part of the changing Indigenous context (Smith 1999/2012, 111), as Indigenous research methods in some areas are now showing a strong impact in research.

We wish to stress in particular that our respective research projects were not developed in an 'Indigenous methodology vacuum'. We were each involved in Sámi research environments and frequently worked with other Indigenous research communities. At the same time that we were working on this book chapter we were also developing and teaching our master's programmes, which were conducted within different disciplines of Sámi education and Indigenous journalism. We realized that the paradigm shift had reached another level by the time we completed our PhDs. We share the experience of completing our $\mathrm{PhDs}$ in the 2010s, a period when many Sámi researchers and other researchers within the Sámi research field were preparing for their own doctoral studies and many new master's programmes were offered in Sámi higher education.

There is a need to address what constitutes the Indigenous research paradigm within the Sámi research context. In this process it is possible to draw on earlier 
theories in this field. Initially, we investigate some of the most important academic publications, which, it would be fair to say, have acquired canonical status in Indigenous studies and research. We also consider a few more recent publications which are not yet canonical. The uses of the concept also overlap; where one paper discusses Indigenous methodology, another refers to a paradigm. Still, they were obviously discussing the same object. We were not surprised by this confusion, as the field is still emerging. These publications are part of an ongoing discussion in which scholars present their thoughts and arguments and then often go on to contradict these very thoughts and arguments as the debate continues and the field expands.

Walter and Andersen (2016, 58-81) analyze the paradigm shift on Indigenous research methodologies in their book Indigenous Statistics: A Quantitative Research Methodology. They review that in former studies a common Indigenous research methodology has been said to be applicable to all Indigenous research, while it has been also claimed that Indigenous methodology can only be replicable in quality research, or that specific research paradigms must be developed according to the history of Indigenous peoples. Walter and Andersen challenge the idea of building an applicable research paradigm for all Indigenous research worldwide. On the other hand, they argue that quantitative research is also needed to obtain statistics on Indigenous peoples, such as research-based knowledge on Indigenous peoples' living conditions in different societies and contexts in a postcolonial era.

The paradigm shift on Indigenous research methodologies is still an ongoing and necessary debate whose roots can be traced back to the 1970s (see Chapters 1 \& 2 in this volume). As early as 1974, the Sámi philosopher Alf Isak Keskitalo spoke about the inequality in research relating to the Sámi. He argued that the power relationships between the Sámi as research target and the outsiders conducting the research were asymmetric (Keskitalo 1976, 1994; Keskitalo \& Eidheim 1974; see also Porsanger 2011). In his critique he also referred to Lappologist research history. Generally, Lappology describes Sámi culture from the outside, a fact that is reflected in the very word used for its name, derived as it was from 'Lapp', an exonym for 'Saami' [Sámi]. In Lappology research it was typical to strengthen the identity of the majority by creating borders and searching for differences. Lappology is burdened by many scientific and social attitudes, such as exoticism, romanticism, misunderstanding, Christianity and cultural and social archaeology (Pulkkinen 2005). However, according to Veli-Pekka Lehtola (2015), this documentation of an old way of life and culture is of benefit to modern research.

There are earlier writings by Sámi authors such as Johan Turi (1910), who can be considered the first Sámi ethnographer. He described Sámi life and living conditions in detail, and his accurate observations can serve as a model 
for writing story-like research. In addition, early Lappologists who also documented Sámi life and produced texts and teaching materials in Sámi were part of the initial process of establishing the Sámi language as an academic language despite the fact that these texts were also producing stereotypical images and othered the Sámi people. However, the real beginning of Sámi as an academic language is recognized to be a later work by the Sámi scholar, Israel Ruong (1969).

Indigenous research is closely connected to decolonization research, which has been inspired by many theorists. Some of the most important profound theorists are Frantz Fanon (1952, 1961/2004), Edward Said (1979) and Paulo Freire (1970). In many ways these writers shaped today's thinking about decolonization and power. Many attempts to build an Indigenous research paradigm have been based on the work of Fanon and other such writers around the world (e.g. Chilisa 2012; Kovach 2009; Smith 1999/2012).

Since the start of the new millennium, several scholars have highlighted the need to collectively re-write the paradigm. Their arguments are supported by Kuokkanen (2000), who wrote that the grounds for a paradigm shift rest on the fact that Sámi knowledge, values and society differ from the way academia has normally understood knowledge. Kuokkanen (2000), Wilson (2001) and Walter and Andersen (2016) are among the more serious attempts to develop a paradigm shift. Thus, we base our practical construction of a paradigm shift especially on the continuum of these previous writings by being aware of other important contributions as well.

Kuokkanen challenged Sámi researchers, claiming that many of them are dissociated from Sámi cultural practice:

Through the Western education system they have been 'immersed' into Western models of doing research which are often characterized by a Cartesian worldview, based on metaphysical dualism and laden with perceptions that derive from the Enlightenment: the fragmentation of human knowledge and the distancing of oneself both physically and mentally from the research object. (Kuokkanen 200o, 413)

Kuokkanen continued, arguing that "this has led to a situation where much Sami research follows and imitates prevailing Western paradigms and Eurocentric thinking without questioning its appropriateness or relevance" (Kuokkanen 200o, 413). Kuokkanen was describing the situation in Sámi research at the end of the last millennium. Today there is still a need to question the appropriateness and relevance of these models. The scope of an Indigenous research 
paradigm confirms the need for "a culturally specific discourse based on Indigenous peoples' premises, values and worldview" (Kuokkanen 2000, 413).

A year after Kuokkanen, Wilson $(2001,176)$ presented a practical solution in his article "What Is an Indigenous Research Methodology?", in which he called for the creation of a separate Indigenous research paradigm. He asserted in his abstract that Indigenous researchers must move beyond merely assuming an Indigenous perspective on non-Indigenous research paradigms. Wilson argues that the Indigenous research paradigm is special because it includes relationality compared to other research paradigms:

An Indigenous paradigm comes from the fundamental belief that knowledge is relational, is shared with all creation, and therefore cannot be owned or discovered. Indigenous research methods should reflect these beliefs and the obligations they imply. (Wilson 2001, 175)

Wilson (2001) also argued that Indigenous research must reflect Indigenous contexts and worldviews, which must come from an Indigenous paradigm rather than from an Indigenous perspective. Paradigm shifts emphasize holistic, culturally relevant research methods that build on a wide understanding of the connection between land and the people:

It is not just interpersonal relationships, not just with the research subjects I may be working with, but it is a relationship with all of creation. It is with the cosmos, it is with the animals, with the plants, with the earth that we share this knowledge. It goes beyond the idea of individual knowledge to the concepts of relational knowledge. (Wilson 2001, 176-177)

A research paradigm involves the establishment of protocols that identify a set of accepted procedures which guide researchers in 'best practices' throughout the entire research process (Wilson 2001), meaning putting effort into building connections, trust and commitment in research processes. Wilson pointed to four important elements which relate to the research paradigm. The first is ontology, or the belief in the nature of reality - that is, the researcher's way of being in the world, together with an awareness of the cultural protocols and understandings of the research participants. The second is epistemology, or how the researcher thinks about reality. This element is essential, as it determines how the knowledge and the meaning of that knowledge are opened - including how it relates to concepts such as truth, belief and justification (Wilson 2001; see also BonJour 2002; Steup 2005). The third, 
the research methodology, serves as a guideline for how a researcher will use his/her thinking (i.e. epistemology) when seeking to gain more knowledge about his/her reality. The fourth, the axiology, is a set of ethics or morals which makes the research a meaningful and safe activity for the participants involved in the study and determines how the research will benefit both the researchers and the participants. These four perspectives - ontology, epistemology, research methodology and axiology - together comprise a research paradigm (Wilson 2001).

\section{3}

\section{Prevailing Research Paradigms}

Wilson (2001) argued that there are four or five dominant Eurocentric paradigms which are used in most research: positivism, post-positivism, critical theory and constructivist theory. Indigenous researchers need to move beyond these, going beyond merely assuming an Indigenous perspective on these nonIndigenous paradigms. Indigenous ontologies, epistemologies, axiologies and methodologies are fundamentally different from, for example, critical theory, which supports the empowerment of disadvantaged groups of people as an Indigenous research methodology should include reciprocity (Wilson 2001). Bagele Chilisa (2012) has suggested another way of classifying research paradigms, using different words for the main research paradigms and presenting them in three pairs: positivism/post-positivism, interpretivism/constructivism and transformative/emancipatory. Barbara Kawulich (2012) presented a slightly different classification, dividing the paradigms into four categories: positivism/post-positivism, constructivism/interpretivism, transformative/emancipatory and the postcolonial Indigenous research paradigm. Walter and Andersen $(2016,17)$ argued against "positioning Indigenous methodologies dichotomously in opposition to Western frames" and against grounding them in "a concept of traditional knowledge and culture 'outside modernity".

We think Wilson's four aspects of a research paradigm, mentioned above as (1) ontology, (2) epistemology, (3) research methodology, and (4) axiology (Wilson 2001, 175) contribute tremendously to a common understanding of a research paradigm. For us, a lack of processing and implementing of an Indigenous research paradigm into practical Sámi research and teaching in tertiary 
education, has made it challenging to start using Indigenous research methodologies in our own research and even more challenging to teach them to our students.

Walter and Andersen (2016) conceptualized research methodology as having three components: a standpoint, a theoretical frame and a method. They placed the Indigenous standpoint at the core of Indigenous research methodology and stressed that a research standpoint is arguably the most important determinant of a research project's methodology:

It pre-exists and fundamentally influences our choices of theoretical frame and method. Most critically, the research standpoint is a fundamental component of all methodologies, not just Indigenous ones. (Walter \& Andersen 2016, 45)

This standpoint is influenced by the Indigenous social position, Indigenous epistemology, Indigenous ontology and Indigenous axiology. There is a sound body of literature on Indigenous epistemology, ontology and axiology, but less work has been done on the concept of the Indigenous social position. Walter and Andersen $(2016,46)$ relied on the work of Pierre Bourdieu (1984), particularly his three dimensions of social space "comprised of social, cultural and economic capital - that creates the filters and frames through which we make sense of the world and our own position within it". They added racial capital as a fourth dimension to an Indigenous position. Race does not make it impossible for non-Indigenous researchers to conduct Indigenous research, but it makes it clear that lack of Indigenousness affects the researcher's social space (Walter \& Andersen 2016, 46-47).

Reflections on the Development of an Indigenous Research Paradigm

Interestingly, Martin Nakata (2002) suggests that Western universities should act as mediators between Indigenous knowledge and Indigenous research. $\mathrm{He}$ points out that scholars should not underestimate the Western research tradition and build any dichotomies between Indigenous and Western understandings. We find his arguments plausible, as we do consider it fruitful rather to critically examine how this tradition should be expanded.

Critiques of the university as a Western concept and as dominated by Western thought are important. In order to criticize it, we must know its history; 
the big question is, however, do we have to discard a 2,ooo-year-old Western research tradition to create a separate 'Indigenous way of knowing within academia'? Is there nothing in the Western tradition of value which should be retained? Our short answer is that we find it hard to discard everything, as this tradition is also a part of our history. We find it reasonable to claim that an Indigenous research paradigm must be built on some existing academic traditions. However, this paradigm must also differ from other paradigms in particular ways. These are important questions. What should be retained and how would an Indigenous research paradigm differ from other research paradigms?

Based on earlier studies discussed in this chapter, we posed and evaluated questions about how and why we worked as we did in our research and educational tasks within the Indigenous methodology field when doing our research and working with our students. We realized that consciously or unconsciously, we were all already implementing Wilson's (2001) ideas in our work. Still, it is fair to say that the use of Indigenous methodologies had yet to become a common practice in Sámi research when we were working on our PhDs, despite the many high-level institutions working with Sámi studies in the Nordic countries and the many academics involved. Nevertheless, we realized that by working at the Sámi University of Applied Sciences, we were already immersed in an environment where Sámi research was frequently discussed as part of Indigenous research and Indigenous research methodologies were at the core of these discussions (see also Keskitalo 2020, 2012; Rasmussen 2020).

In the Sámi University of Applied Sciences, several experienced Sámi academics guided us into Sámi research. Scholars such as Jan Henry Keskitalo, Aimo Aikio, Vuokko Hirvonen, Kristine Nystad, Jelena Porsanger, Asta Balto and Liv Østmo not only 'talked the talk' when it came to Indigenous research, being among the leading theorists in this field, they also 'walked the walk' and supervised us in our own work. We are extremely grateful to have been involved in these discussions and knowledge transmissions. It is also worth mentioning that while we were working on our PhDs we were able to take part in international Indigenous research conferences where new ideas were presented and old ideas challenged, and the Sámi University of Applied Sciences arranged annual research conferences which included Indigenous research methodologies on the agenda. Several leading Indigenous scholars also visited our research environment.

Nevertheless, there is a contradiction here. Many students and researchers working in Indigenous studies or related fields were unsure of the discourse around the paradigm shift and where this kind of work was leading. Furthermore, the various organizations involved operated mostly independently and 
in their own countries, despite a few attempts to work cooperatively in the area of Sámi research and teaching. This reality reveals how powerful the dominant paradigm at universities is and how difficult it is to change that course.

We need to construct and evaluate our own roles as researchers and understand our obligations. We are also interested in discovering whether this method will help to build relationships with one another as researchers and with our research topics, and whether it will prompt further development based on this consciousness. This cannot be the responsibility of individual researchers alone. We need leadership on all levels at universities and we still need more of an upheaval in the world of science so that the present power struggle is replaced by participation and commitment, as Kuokkanen $(2007,156-157)$ has called for in Reshaping the University.

Next, we will illuminate our research path by discussing how we position ourselves, connect with each other, collaborate and give back. In doing so we intend to formulate the paradigm shift as a concrete practice based on Wilson's (2001) analogical frame of connectedness. We believe that this will work in practice, as it is the research data which has helped us to build a theory around our thoughts concerning the Indigenous research paradigm.

The Indigenous research paradigm relates to the quality of research by positioning the research, the researcher and the research topic and by explaining the motivation for the research and the connection of the Indigenous community to the topic (Russell-Mundine 2012). In doing so, one is writing about one's own motivation, standpoint and aim in conducting the research. Readers can then draw their own conclusions about how valuable the research is and how broadly the research phenomenon can be applied. This constitutes part of the research quality and reliability in Indigenous research. Due to this requirement, we were aware of the significance of presenting in our texts who we are, what we are doing and what our backgrounds are.

This starting point of personal experiences and backgrounds gave us a strong basis for researching the topics we planned to investigate. In addition, our workplaces and research groups were committed to supporting the Sámi community through the research topics selected. We felt that, because of our background, education and membership in both our communities and our research groups, we were supported in many ways in undertaking this research. All this support makes us feel privileged; the question is however, is Indigenous research this well supported in other research institutions all over the world? 
Designing a research project requires researchers to take seriously the requirement of 'free, prior and informed consent'. We prepared our research project collaboration based on the national and institutional data protection requirements to be met based on which country your institution is based, and in which country you want to carry out research. Firstly, based on that, in Norway it was mandatory asking permission from the existing national research body NSD - Norwegian Centre for Research Data or possibly university ethical boards in Finland, based on funding and research design requirements. Secondly, if the data consists of data gathered at schools, like our data did, permission needs to be asked of the school head, teachers, parents and pupils. Some of the researchers had created a reference group. According to good practices in Indigenous research we should also ask permission from the Sámi local societies. We solved this requirement by visiting the teacher meetings, parents and pupils and presented our research in media and seminars and conferences. In addition, it is meaningful to also meet authorities, Indigenous politicians and NGO representatives from local associations. However, some of us had difficulty in defining the Indigenous society. It was challenging, if not quite impossible, to separate the local society from the local Indigenous society in some of the municipalities where we conducted our research. According to our knowledge, Sámis comprise the majority in some of these municipalities and are currently well represented in politics, bureaucracy and other important positions (Keskitalo 2010; Rasmussen 2013; Äärelä 2016; Rahko-Ravantti 2016).

The guiding point of our research was the idea of designing research projects that would benefit the Indigenous Sámi local communities (Barron 2002). The idea of benefit is closely connected to research ethics (Bull 2002). We had followed the discourses in the Sámi society and were aware of the fields in which Sámi and local authorities needed more knowledge about Sámi education matters. We used this important background information ourselves, and in our working groups, to identify the type of research needed in these societies.

We also selected research topics based on our lifetime experiences as Sámis in Sámi communities and the professional knowledge we shared with our colleagues and supervisors. Each author prepared carefully, negotiating with communities and speaking to other researchers as well as to principals, teachers, parents and pupils. Before each interview the interviewee(s) were informed and gave their prior consent.

Throughout our work we were determined that the Indigenous society must be involved in the research project and must receive something in return. First 
of all, we decided that our participants should be informed about the results of the research and the researcher's recommendations for improving their situation; in our case, this involved education and language revitalization, which are closely related issues.

\section{$8 \quad$ Giving Back}

'Giving back' was a useful guideline for our research. This is because it reflects our way of thinking about research. We conduct research because our people have important knowledge to offer when they explain their views on their own realities. When we receive their knowledge we take upon ourselves a responsibility for the use of this knowledge to improve the life for our own people, and also for giving jointly constructed knowledge back to the knowledge holders to improve the situation.

Giving back is a concept which affects the whole research process, not just the methodologies used to conduct the research. It shapes how the research topic is chosen, the research questions, the reporting and the researcher's responsibilities to the people who contribute to the study throughout the whole research process. It does not stop when the research project comes to an end: The people we work with follow us. They remain a part of our lives as researchers, and we remain a part of their lives. We will meet them again at formal and informal occasions later in our lives.

\section{Concretizing Relational Knowledge in the Indigenous Research Paradigm}

In this section, we construct and process relational knowledge in Indigenous and Sámi research and finally pull it all together, including how we understand relational knowledge, as shown in Figure 3.1. Figure 3.1 illustrates the process of selecting the topic of the research, asking permission and conducting the research through collaboration, dissemination, teaching and learning. Relational knowledge (Wilson 2001) is concretized by representing the process of research in the image as traditional braiding (ruvdet in North Sámi language) based on our construction of our research projects. Ruvdet is the action you do to make a Sámi braiding band.

Constructing a topic involves thinking about and searching for what is worthy of being researched. It is a process in which the researcher makes choices 


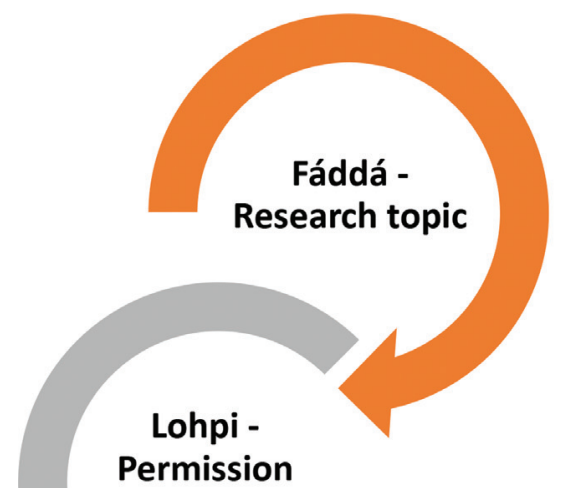

Permission
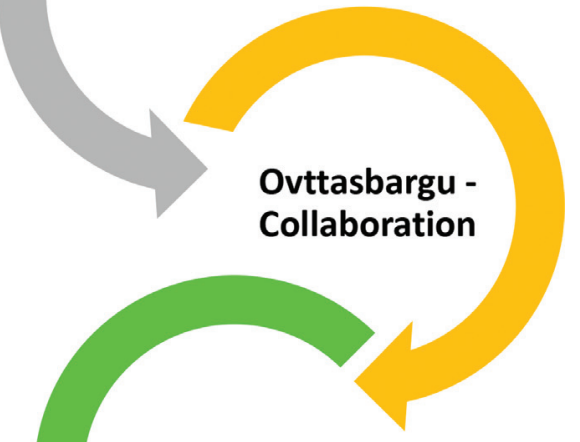

Dieđu juohkin Dissemination

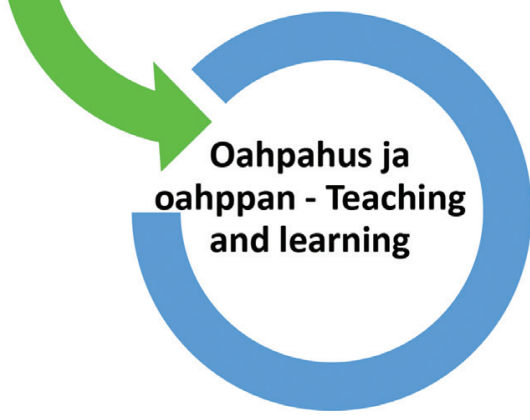

FIGURE 3.1

Ruvdet as processing relational knowledge in Sámi research

in cooperation with and with the support of a research group, the academic community and different practitioners, in a particular Indigenous community. Another part of the process is asking permission. As researchers, we each dealt differently with this task when conducting research projects for our PhDs.

First, our standpoint led us to a research topic, as it helped us identify where there was a need for research. Each researcher became involved in the research question by communicating and cooperating with the community, or just by being a part of the Indigenous community. The second step was to ask 
permission. As researchers, we each approached this aspect of our work differently. Some of us felt that we already had a sufficient understanding of the research needed and therefore a mandate for research was gained. In addition, we were all already connected to our research projects, which meant that we were all part of a bigger research project; we had the support of our supervisors and colleagues, and we cooperated with other researchers both at a national Sámi level and at an international Indigenous level. We feel that we have all worked intensively to get the permissions needed to conduct our research in schools. Although we already had the required permission at the institutional level, we still needed individual consent prior to any personal interactions. This was obtained in two ways, and required each researcher to clarify the research aims, tasks and ethics. Third, conducting the research project required multiple sensitivities and responsibilities in relation to cooperating with the community. The need for sensitivity varied, but the most important point was close communication. Fourth, we disseminated our new knowledge in different ways and used the full range of media and platforms, from news stories, parents' meetings and scientific articles to local and international conferences. Fifth, the teaching and learning is now included in what we teach the students in the master's programmes and in our teaching of in-service teacher education at an advanced level.

\section{Discussion}

In this chapter we discussed the need for the further development and vocabulary of an Indigenous research paradigm in the context of Sámi research. Elaborating the basis for this chapter in our gáfestallan talking circles mentioned in the beginning, we agreed that there is a need for such a paradigm. During our work we constructed the content of a paradigm critically evaluating former literature in this field and our actions as educators and researchers. Our intention is to find ways to develop Sámi education and Sámi educational research through teaching models and practices, and so we teach research using Indigenous methodologies. In some ways, we see Indigenous research as Graham Smith (2003) defined it - as a field where it is more important to think about who the research is done for and for what reason. The method itself is not the focus, as which one is chosen depends on the research design and the questions posed.

After elaborating our former research processes, they seem to be conducted in appropriate ways as we were connected to our own culture, having Sámi values and being aware of our own knowledge systems. By investigating what we have done as researchers and educators in higher education, we can clearly 
see that we are not disconnected, but are part of our societies, working for our communities. As a concrete Indigenous paradigm was not available, even though there have been individual attempts to resolve this challenge, we all felt in the course of our research that such a paradigm would have been more appropriate for us. We did, though, include Indigenous methodology in our research but we were unable to name a specific Indigenous research paradigm at that time. We therefore identify with Kuokkanen's $(2000,413)$ closing philosophical point, which she describes as a prescription for "a culturally specific discourse, based on Indigenous peoples' premises, values and worldview".

We also subscribed to the thoughts of Walter and Andersen (2016), as they placed the Indigenous standpoint at the heart of Indigenous research methodologies and stressed that it is arguably the most important determinant of a research project's methodology. We consider that these authors have already provided the basis for an Indigenous research paradigm, and we believe that Walter and Andersen in particular have made an important contribution to this field. We think that the reason we could not find any serious flaws in our own research is that we all had Sámi research standpoints from the beginning of our projects. It is imperative that researchers are conscious of their research standpoints in the future, as this factor determines all other aspects of a research project and ultimately the research paradigm.

As a result of this book chapter project that has been carried out in the Network for Indigenous Research Methods in Academia (2017-2019), we realized that Wilson (2001) serves as a well-developed basis for our work. We were able to concretize what the relational research paradigm means in Sámi research and how this relation should be treated in different phases of the research. We call this process by the Sámi term 'ruvdet' as those Indigenous concepts serve as a profound starting point in one's work and in one's working processes. Practically, this means that there is a beginning before you can act, you have to make a work to function, create a basis and a plan, then you are able to act. In the end, to finalize the work in an Indigenous way, you also have to carry out some actions to take into account certain requirements. We are already implementing this into new research and will spread these thoughts to colleagues and students who will engage with them.

\section{References}

Äärelä [Äärelä-Vihriälä], R. (2016). Datii leat dušše dat giella-Se ei olevain se kieli. Tapaustutkimus saamenkielisestä kielipesästä saamelaisessa varhaiskasvatuksessa [It is not 
just the language - A case study of a Sámi language nest in Sámi early childhood education] (PhD dissertation). Acta Universitatis Lapponiensis 335. University of Lapland.

Barron, A. (2002). Traditional knowledge, Indigenous culture and intellectual property rights. In Den nasjonale forskningsetiske komité for samfunnsvitenskap og humaniora (NESH) (Ed.), Samisk forskning og forskningsetikk [Sámi research and research ethics] (pp. 56-87). Publiksjon nr. 2. Forskningsetiske komiteer.

BonJour, L. (2010). Epistemology: Classic problems and contemporary responses (2nd ed.). Rowman \& Littlefield.

Bourdieu, P. (1984). Distinction: A social critique of the judgement of taste (R. Nice, Trans.). Harvard University Press.

Bull, T. (2002). Kunnskapspolitikk, forskningsetikk og det samiske samfunnet [Knowledge policy, research ethics and the Sámi society]. In Den nasjonale forskningsetiske komité for samfunnsvitenskap og humaniora (NESH) (Ed.), Samiskforskning og forskningsetikk [Sámi research and research ethics] (pp. 6-21). Publiksjon nr. 2. Forskningsetiske komiteer.

Chilisa, B. (2012). Indigenous research methodologies. Sage.

Fanon, F. (1952). Black skin, White masks. Editions de Seuil.

Fanon, F. (2004). The wretched of the earth (R. Philcox, Trans.). Grove Press. (Original work published 1961)

Freire, P. (1970). Pedagogy of the oppressed. Continuum.

Kawulich, B. (2012). Selecting a research approach: Paradigm, methodology and methods. In C. Wagner, B. Kawulich, \& M. Garner (Eds.), Doing social research: A global context (pp. 51-61). McGraw Hill.

Keskitalo, A. I. (1976). Samfunnsforskning og minoritetsamfunn [Social research and minority communities]. Acta Borealia B. Humanoria, 13, 15-42.

Keskitalo, A. I. (1994). Research as an inter-ethnic relation. Arctic Centre Reports 11/ Dieđut 7/1994. Arctic Centre.

Keskitalo, A. I., \& Eidheim, H. (1974). Samfunnsforskning og minoritetsamfunn: Foredrag på Nordisk Etnografmøte Tromsø 1974 [Social research and minority society: Lecture at the Nordic Ethnograph Meeting Tromsø 1974]. Tromsø Museum.

Keskitalo, P. (2010). Saamelaiskulttuurin sensitiivisyyttä etsimässä kasvatusantropologian keinoin [Searching for the cultural sensitivity of Sámi school through educational anthropology] (PhD dissertation). Dieđut 1/2010. Sámi allaskuvla.

Keskitalo, P. (2012). Pioneering on research on Sámi education - deliberations about a researcher's position. In K. Määttä (Ed.), Obsessed with the doctoral theses. Supervision and support during the dissertation process (pp. 25-31). Sense.

Keskitalo, P. (2020). Becoming a Sámi scholar. Narrating Sámi education researcher's path. In K. Trimmer, D. Hoven, \& P. Keskitalo (Eds.), Indigenous postgraduate education. Intercultural perspectives (pp. 163-178). IAP. 
Kovach, M. (2009). Indigenous methodologies - Characteristics, conversations, and contexts. Toronto University Press.

Kuhn, T. S. (2012). The structure of scientific revolutions (5oth anniversary ed., 4nd ed.). University of Chicago Press. (Original work published 1962)

Kuokkanen, R. (2000). Towards an 'Indigenous paradigm' from a Sami perspective. The Canadian Journal of Native Studies, 2, 411-436.

Kuokkanen, R. (2007). Reshaping the university: Responsibility, Indigenous epistemes, and the logic of the gift. University of British Columbia Press.

Lehtola, V.-P. (2015). Saamelaiset. Historia, yhteiskunta, taide [The Sámi people: History, society and art]. Kustannus-Puntsi.

Löf, A., \& Stinnerbom, M. (2016). Making collaboration work - Reflections from both sides. In A.-L. Drugge (Ed.), Ethics in Indigenous research past experiences - Future challenges (pp. 137-155). Umeå University.

Nakata, M. (2002). Indigenous knowledge and the cultural interface: Underlying issues at the intersection of knowledge and information systems. IFLA Journal, 28(5-6), 281-291.

Porsanger, J. (2011). The problematisation of the dichotomy of modernity and tradition in Indigenous and Sámi contexts. Dieđut, 1, 225-252.

Pulkkinen, R. (2005). Research history of the lappology. In U.-M. Kulonen, I. SeurujärviKari, \& R. Pulkkinen (Eds.), The Saami - A cultural encyclopaedia (pp. 5o6). Finnish Literature Society.

Rahko-Ravantti, R. (2016). Saamelaisopetus Suomessa: tutkimus saamelaisopettajien opetustyöstä suomalaiskouluissa [Sámi education in Finland: Research about Sámi teachers' work at Finnish schools] (PhD dissertation). University of Lapland.

Rasmussen, T. (2013). 'Go ealáska, de lea váttis dápmat': Davvisámegiela etnolingvisttalaš ceavzinnávccaid guorahallan guovtti gránnjágielddas Deanus ja Ohcejogas 2000logu álggus. ['It's difficult to tame when it gets wild': The ethno-linguistic vitality of North Sámi in two neighbouring municipalities Deatnu/Tana and Ohcejohka/Utsjoki at the beginning of the twenty-first century] ( $\mathrm{PhD}$ dissertation). Arctic University of Norway.

Rasmussen, T. (2020). My PhD story. A lifelong story of coincidences. In K. Trimmer, D. Hoven, \& P. Keskitalo (Eds.), Indigenous postgraduate education. Intercultural perspective (pp. 285-297). IAP.

Ruong, I. (1969). Samerna [The Sámi people]. Bonnier.

Russell-Mundine, G. (2012). Reflexivity in Indigenous research: Reframing and decolonizing research? Journal of Hospitality and Tourism Management, 19(1), 85-90.

Saïd, E. (1979). Orientalism. Vintage.

Smith, G. H.(2003). Indigenous struggle for the transformation of education and schooling. Keynote address to the Alaskan Federation of Natives (AFN) Convention, Anchorage, Alaska. https://faculty.washington.edu/pembina/all_articles/Smith_G2003.pdf 
Smith, L. T. (2012[1999]). Decolonizing methodologies: Research and Indigenous peoples. Zed Books.

Steup, M. (2005). Contextualism and conceptual disambiguation. Acta Analytica, 20, $3^{-15}$.

Turi, J. (1910). Muittalus samid birra: Atlas med 14 tavler [The story of the Sámi people:An atlas with 14 boards]. I distribution Nordiska bokhandeln.

Walter, M., \& Andersen, C. (2016). Indigenous statistics: A quantitative research methodology. Routledge.

Wilson, S. (2001). What is Indigenous research methodology? Canadian Journal of Native Education, 25(1), 175-179. 